\title{
Neighborhood Income and Income Distribution and the Use of Cigarettes, Alcohol, and Marijuana
}

\author{
Sandro Galea, MD, DrPH, Jennifer Ahern, MPH, Melissa Tracy, David Vlahov, PhD
}

Abstract: Evidence about the relationship between contextual variables and substance use is conflicting. Relationships between neighborhood income and income distribution and the prevalence and frequency of substance use in 59 New York City (NYC) neighborhoods were assessed while accounting for individual income and other socio-demographic variables. Measures of current substance use (in the 30 days prior to the survey) were obtained from a random-digit-dial phone survey of adult residents of NYC and data from the 2000 U.S. Census to calculate median neighborhood income and income distribution (assessed using the Gini coefficient). Among 1355 respondents analyzed (female $=56.2 \%$, mean age $=40.4), 23.9 \%$ reported cigarette, $40.0 \%$ alcohol, and $5.4 \%$ marijuana use in the previous 30 days. In ecologic assessment, neighborhoods with both the highest income and the highest income maldistribution had the highest prevalence of drinking alcohol $(69.0 \%)$ and of smoking marijuana $(10.5 \%)$ but not of cigarette use; there was no clear ecologic association between neighborhood income, income distribution, and cigarette use. In multilevel multivariable models adjusting for individual income, age, race, sex, and education, high neighborhood median income and maldistributed neighborhood income were both significantly associated with a greater likelihood of alcohol and marijuana use but not of cigarette use. Both high neighborhood income and maldistributed income also were associated with greater frequency of alcohol use among current alcohol drinkers. These observations suggest that neighborhood income and income distribution may play more important roles in determining population use of alcohol and marijuana than individual income, and that determinants of substance use may vary by potential for drug dependence. Further research should investigate specific pathways that may explain the relationship between neighborhood characteristics and use of different substances.

(Am J Prev Med 2007;32(6S):S195-S202) (c) 2007 American Journal of Preventive Medicine

\section{Introduction}

$\longrightarrow$ igarette and alcohol use are highly prevalent in the United States, with $69.7 \%$ of Americans having smoked in their lifetime, $30.6 \%$ in the past year, and $27.7 \%$ in the past month, and the majority of Americans reporting alcohol use in their lifetime $(81.3 \%)$, in the past year $(64.0 \%)$, and in the past month $(51.7 \%) .{ }^{1}$ Illicit drug use of any kind, while less common, is still present in a substantial proportion of the population, with $35.8 \%$ of Americans reporting use in their lifetime, $10.6 \%$ in the past year, and $6.2 \%$ in the last month. ${ }^{1}$ The use of drugs is associated with a wide range of risks, including both symptoms of

From the Department of Epidemiology, University of Michigan (Galea, Ahern, Tracy), Ann Arbor, Michigan; the Center for Urban Epidemiologic Studies, New York Academy of Medicine (Galea, Ahern, Tracy, Vlahov), and Department of Epidemiology, Columbia University Mailman School of Public Health (Galea, Vlahov), New York, New York; and Department of Epidemiology, Johns Hopkins Bloomberg School of Public Health (Vlahov), Baltimore, Maryland

Address correspondence and reprint requests to: Sandro Galea, MD, DrPH, Department of Epidemiology, University of Michigan School of Public Health, 1214 South University, Room 243, Ann Arbor MI 48104-2548. E-mail: sgalea@umich.edu. dependence (e.g., reducing important activities due to the use of drugs) and abuse (e.g., driving a car more than once while intoxicated, getting into trouble with superiors or coworkers due to intoxication). Despite a substantial extant body of research on substance use, there is very little research about the role of contextual (or group-level) variables in determining substance use and misuse. ${ }^{2,3}$

Recent research has shown that contextual (or grouplevel) variables are important determinants of health even after accounting for differences in individual-level characteristics. ${ }^{4,5}$ For the purposes of this paper, "contextual" variables refer to aggregate units representing characteristics of geographic areas and individuals in those areas, distinct from individuals' perceptions of those areas. Although this area of research is relatively new, it long has been suggested that contextual factors are the most important determinants of population health and population inequalities in disease. ${ }^{5}$ In the past decade, widespread acceptance of improved statistical techniques to combine group-level and individual-level data in regression modeling (frequently referred to as multilevel modeling) and a growing interest in societal influences on 
health have resulted in a proliferation of epidemiologic research assessing the relationships between contextual characteristics and health.

Two of the contextual variables that have been subject to the most research are aggregate income and income distribution. There is ample evidence for the relationship between aggregate income and health, both in ecologic analyses and in multilevel analyses that account for individual-level income. Aggregate income has been associated with overall mortality, ${ }^{7,8}$ coronary heart disease, ${ }^{9}$ and respiratory disease. ${ }^{10}$ It has been postulated (although tested empirically in relatively few studies) that factors such as the limited availability and accessibility of health services, poor infrastructural conditions, and psychosocial stress may mediate the relationships between aggregate income and health. ${ }^{5}$

More controversially, income distribution has also been suggested as an important determinant of health, even after accounting for aggregate and individual-level income. Ecologic evidence has long suggested that countries with more egalitarian distribution of income have lower mortality rates. ${ }^{11}$ In the early 1990 s, a series of publications spurred further interest in the role of income distribution as an area-level determinant of health. ${ }^{6}$ Recent empiric evidence suggests that inequalities in income distribution contribute to health differentials between states and may contribute to some of the racial/ethnic and socioeconomic disparities in health in the U.S. ${ }^{12,13}$ Other work has failed to document an association between inequalities in income distribution and health. ${ }^{14}$ The principal proponents of the hypothesized relationship between income distribution and health suggest that perceived and actual inequity, caused by discrepancies in income distribution, erode social trust and diminish the social capital that shapes societal well-being and individual health. ${ }^{15,16}$

There has been relatively little research that has assessed the potential relationships between contextual variables and substance use behavior among adults and most of this work has focused on neighborhood socioeconomic status. In one study, Curry et al. ${ }^{17}$ showed that community-level characteristics (e.g., residential stability, unemployment) were associated with attitudes toward smoking, although this study did not assess frequency of smoking. A subsequent study showed that people living in more economically deprived areas (including variables such as employment levels and crowding) were more likely to smoke than people living in less-deprived areas, even after accounting for individual-level socioeconomic status. ${ }^{18}$ Corroborating these findings, others have shown that living in areas with lower mean income is associated with a greater likelihood of smoking after accounting for individuallevel variables. ${ }^{10,19-21}$ However, the number of cigarettes smoked has not been found to be associated with levels of neighborhood deprivation. ${ }^{21,22}$ Additionally, while some studies have suggested that heavy drinking is more prevalent in areas with high levels of neighborhood disorder (high unemployment, crime, abandoned houses), ${ }^{23}$ other studies have observed the highest levels of alcohol consumption in the least-deprived neighborhoods, ${ }^{24}$ or failed to find an association between neighborhood deprivation or disorder and alcohol consumption. ${ }^{21,25}$

Although there is a growing body of work assessing the relationship between neighborhood context and the use of cigarettes, alcohol, and illicit drugs among adolescents, that literature is not reviewed here since determinants of substance use may be substantially different among youth compared to adults. Only a few studies have assessed the relationship between income distribution and individual substance use among adults. One multilevel study showed that residence in neighborhoods with poorly distributed income was associated with a higher likelihood of death due to accidental drug overdose. ${ }^{26}$

Thus, the existing literature suggests that there may be a relationship between contextual variables and individual substance use behavior even after accounting for individual characteristics. However, the observation of statistically significant associations between context and use of different substances has varied between studies. The inconsistencies in findings may demonstrate that contextual characteristics affect substance use only in certain places or that drugs with different actions (e.g., stimulants vs depressants) may be expected to have different determinants. In addition, such discrepancies may be explained by differences in study design and assessed behaviors. This paper contributes to the investigation of relationships between contextual variables and substance use behavior by assessing the relationships between neighborhood-level income and income distribution and cigarette, alcohol, and marijuana use. By considering multiple substances within the same study, potential differences in the relationship of neighborhood income and income distribution with the use of different substances may be illuminated.

\section{Methods}

\section{Individual-Level Variables}

Individual-level variables for this study were obtained from a cross-sectional random-digit-dial (RDD) household telephone survey that included measures of substance use. The survey, carried out between March 25 and June 25, 2002, was designed to assess mental health in the New York City (NYC) metropolitan area in the aftermath of the September 11 terrorist attacks in NYC. The sampling frame for the survey included all adults in the NYC metropolitan area with oversampling of residents in NYC; this analysis is limited to residents of NYC. Further discussions of the methods and results from this survey can be found elsewhere. ${ }^{27,28}$ 
Respondents were interviewed using a structured questionnaire. The primary outcome variables for this analysis were respondents' cigarette smoking, alcohol drinking, and marijuana smoking. For each of the three substances respondents were asked the following series of questions. First, the respondent was asked if he/she had used the substance in the previous 12 months (e.g., "Have you smoked cigarettes in the last 12 months?"). Respondents who answered "Yes" to this question were asked to report on how many days that they had used the substance in the 30 days prior to the survey, and the average number of times that the substance was used per day. This information was used to calculate the total number of cigarettes smoked, number of alcoholic drinks consumed, and number of times that marijuana was smoked in the past 30 days. Of the sample of 1355 NYC residents, 10 respondents $(0.7 \%)$ were missing data for the use of cigarettes in the past 30 days, $21(1.5 \%)$ for the consumption of alcohol, and 18 $(1.3 \%)$ for marijuana use. For the analyses presented here, use of each of these substances was examined individually. The survey also assessed demographic characteristics including age, race/ethnicity, gender, yearly household income, and education.

\section{Neighborhood Definition}

New York City is divided into 59 residential community districts (CDs) by the Department of City Planning. These CDs delineate meaningful neighborhoods within NYC, ${ }^{29-31}$ and were used as neighborhood units in these analyses. The CDs will be referred to as neighborhoods hereafter. These neighborhood units have previously been used in a study of the relationship between neighborhood income and income distribution and likelihood of drug overdose. ${ }^{26}$

\section{Neighborhood-Level Variables}

Data from the 2000 U.S. Census for the 59 neighborhoods in NYC were used to obtain median household income and to calculate the Gini coefficient as a measure of income distribution. ${ }^{32}$ Incorporating more than just the range of incomes in a given area, the Gini coefficient provides information about the distribution of income and the extent of income inequality, and has been used in a number of studies assessing the relationship between income distribution and health. ${ }^{14,26,33}$ The Gini coefficient is calculated from a Lorenz curve with the proportion of the population from poorest to richest represented on the $\mathrm{x}$-axis and the proportion of the population's income on the $y$-axis. The Gini coefficient is the area between the diagonal line of no inequality and the concave line representing the income distribution in a particular population. Thus, a Gini coefficient of 0 denotes perfectly equitable income distribution, whereas a Gini coefficient of 1.0 represents maximal maldistribution. The Gini coefficient was rescaled to range from 0 to 100 for this analysis so that regression parameter estimates could be more easily interpreted.

\section{Statistical Analyses}

Sampling weights were used in all analyses to correct potential selection bias related to the number of household telephones, people in the household, and over-sampling. Demographic characteristics of the survey population were described and compared to the demographic distribution suggested by the 2000 U.S. Census. ${ }^{32}$ All survey respondents were geocoded to their neighborhood of residence using their residential address. Respondents who could not be geocoded (due to missing or incorrect addresses) were excluded from these analyses; characteristics of the people included in these analyses were compared to those who were excluded to ensure that systematic bias was not introduced through exclusion of these participants.

Logistic regression was used to test the bivariate relationships between the individual- and neighborhood-level covariates of interest and the likelihood of use of each of the three substances. Linear regression was used to test the bivariate relationships between covariates and the frequency of substance use among those who had used a substance. Since the total number of people who had used marijuana in the 30 days before the survey was small (92), the determinants of frequency of marijuana use were not assessed. The linearity of the relationship between each covariate and outcome was assessed using differences in log-likelihood ratios $(p<0.1)$, as it has been suggested that there is a nonlinear relationship between, for example, income and health. ${ }^{34,35}$ Evidence of a nonlinear relationship between median neighborhood income and mean number of cigarettes smoked in the past 30 days was found. The relationship between median neighborhood income and frequency of smoking was best described by a quadratic income term, and median neighborhood income was subsequently modeled in quadratic form in the model predicting frequency of smoking.

To describe the ecologic relationships between neighborhood income and income distribution and use of each substance, neighborhood median income was categorized into low ( $\$ 16,000$ to $\$ 32,424)$, medium $(\$ 32,425$ to $\$ 43,089)$, and high $(\$ 43,090$ to $\$ 79,475)$, while the neighborhood Gini coefficient was categorized into low inequality (0.375 to $0.432)$, medium inequality ( 0.433 to 0.465$)$, and high inequality $(0.466$ to 0.513$)$. The prevalence of the use of each substance by thirds of median neighborhood income and Gini coefficient (e.g., low income and low inequality, low income and medium inequality, and so on) was then calculated and graphed. Generalized estimating equations were used to fit separate multilevel multiple logistic regression models that assessed the relationship among median neighborhood income, income distribution, and likelihood of use of each of the three substances, while controlling for individual age, gender, race/ethnicity, income, and education. ${ }^{36,37}$ Among those who had used cigarettes and among those who had used alcohol in the month before the survey, separate multilevel, linear, generalized estimating equation models were fit to assess the relationships among neighborhood median income and income distribution and the number of cigarettes smoked and the number of alcoholic drinks consumed, respectively, in the 30 days before the survey assessment.

\section{Results}

Overall, 1570 people participated in the RDD survey. Of these, 1355 were able to be linked to their neighborhood of residence, and all analyses presented were restricted to this latter sample. There were no significant differences in the characteristics of the people 


\begin{tabular}{|c|c|c|}
\hline & $n$ & $\%^{a}$ \\
\hline \multicolumn{3}{|l|}{ Age (years) } \\
\hline $18-24$ & 144 & 15.95 \\
\hline $25-34$ & 357 & 27.75 \\
\hline $35-44$ & 279 & 18.33 \\
\hline $45-54$ & 248 & 18.04 \\
\hline $55-64$ & 148 & 10.95 \\
\hline$\geq 65$ & 134 & 8.98 \\
\hline \multicolumn{3}{|l|}{ Gender } \\
\hline Male & 616 & 43.83 \\
\hline Female & 739 & 56.17 \\
\hline \multicolumn{3}{|l|}{ Race/ethnicity } \\
\hline White & 682 & 35.65 \\
\hline Asian & 102 & 6.26 \\
\hline African American & 220 & 24.24 \\
\hline Hispanic & 291 & 29.69 \\
\hline Other & 40 & 4.15 \\
\hline \multicolumn{3}{|l|}{ Income } \\
\hline$\geq \$ 100,000$ & 213 & 11.33 \\
\hline$\$ 75,000-\$ 99,999$ & 102 & 9.76 \\
\hline$\$ 50,000-\$ 74,999$ & 196 & 16.08 \\
\hline$\$ 40,000-\$ 49,999$ & 93 & 6.68 \\
\hline$\$ 30,000-\$ 39,999$ & 134 & 14.91 \\
\hline$\$ 20,000-\$ 29,999$ & 142 & 16.54 \\
\hline$<\$ 20,000$ & 265 & 24.71 \\
\hline \multicolumn{3}{|l|}{ Education } \\
\hline Graduate degree & 255 & 10.55 \\
\hline College degree & 442 & 27.87 \\
\hline Some college & 239 & 21.60 \\
\hline $\begin{array}{l}\text { High school Graduate/ } \\
\text { GED }\end{array}$ & 248 & 23.99 \\
\hline$<$ High school graduate & 169 & 15.99 \\
\hline Total & 1355 & 100.00 \\
\hline
\end{tabular}

${ }^{a}$ Weighted percent to account for number of household telephones, people in the household, and over-sampling.

included in these analyses and the 215 people excluded from the analyses. Table 1 presents baseline characteristics of the sample used for these analyses. Mean age was 40.4 (standard deviation 12.9), $43.8 \%$ were male, 35.7\% were white, 6.3\% Asian, 24.2\% African American, and $29.7 \%$ Hispanic. A plurality of participants had an income $<\$ 20,000(24.7 \%), 16.5 \%$ had an income between $\$ 20,000$ and $\$ 29,999$, and $16.1 \%$ had an income between $\$ 50,000$ and $\$ 74,999$. Characteristics of this group were comparable to characteristics of the general NYC population obtained from the 2000 U.S. Census. ${ }^{32}$ Overall, $308(23.9 \%)$ people had smoked, 661 (40.0\%) had used alcohol, and $92(5.4 \%)$ had used marijuana in the 30 days before the survey. These 30-day prevalences of substance use are comparable to national 30-day prevalence estimates of use of these substances. ${ }^{38}$ Among those who had smoked, a mean of 262 cigarettes were smoked in the past 30 days (standard deviation 258.7). Among those who drank alcohol, a mean of 18 alcoholic drinks were consumed in the 30 days before the survey (standard deviation 20.9). Median neighborhood income across $59 \mathrm{NYC}$ neighborhoods was $\$ 36,470$ (range $\$ 16,000$ to
$\$ 79,475$ ), and the mean Gini coefficient was 0.45 (range 0.37 to 0.51 ).

For the purposes of illustration, the prevalence of past 30-day use of each substance was calculated by thirds of neighborhood median income and Gini coefficient. Figure 1 shows the relationships between Gini coefficient, median income, and prevalence of cigarette smoking. None of the 59 NYC neighborhoods were classified as having both low income and low income inequality. Neighborhoods with the highest median income and the middle third of Gini coefficient had the highest prevalence of cigarette smoking $(34.3 \%)$, while neighborhoods with the highest median income and with the highest Gini had the lowest prevalence of cigarette smoking (18.5\%). As shown in Figure 1, there was no clear relationship between neighborhood prevalence of cigarette smoking, median income, and Gini coefficient.

Figure 2 shows the relationships among Gini coefficient, median income, and the prevalence of alcohol consumption. There was a linear increase in the prevalence of alcohol use along both the median income and the Gini axes, such that the neighborhood with the highest median income and the highest Gini had the highest prevalence of alcohol use $(69.0 \%)$.

Figure 3 shows the relationship between Gini coefficient, median income, and the prevalence of marijuana smoking. This relationship approximated the pattern observed for alcohol use, demonstrating an increase in the prevalence of marijuana smoking along both the median income and the Gini axes, and with the highest prevalence of marijuana smoking $(10.5 \%)$ in the neighborhood with the highest median income and the highest Gini.

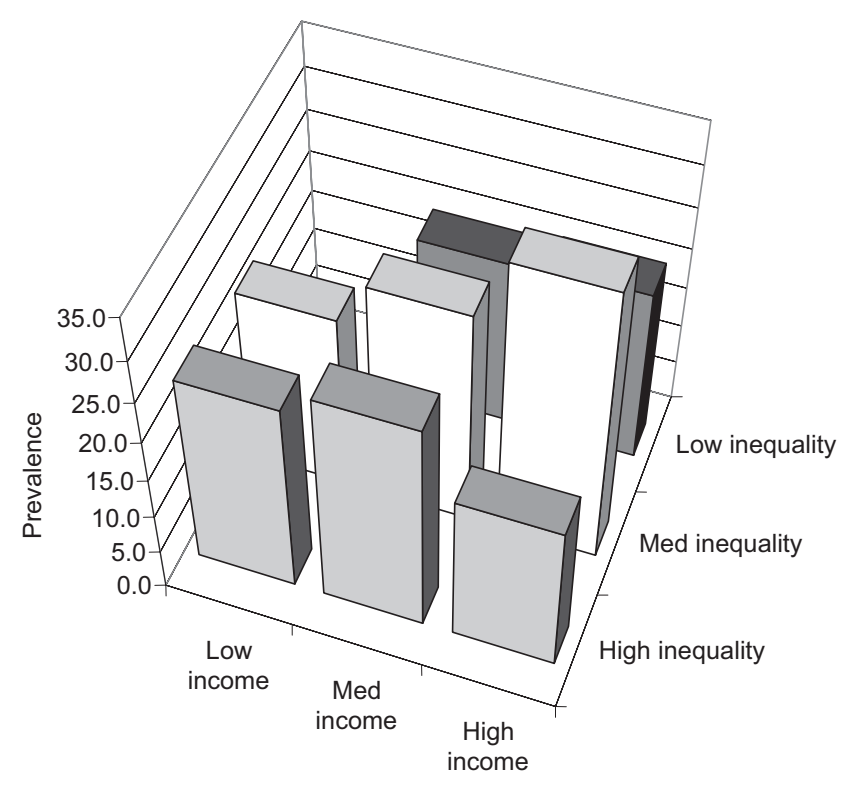

Figure 1. Gini coefficient (inequality), median income, and prevalence of cigarette smoking in New York City neighborhoods. 


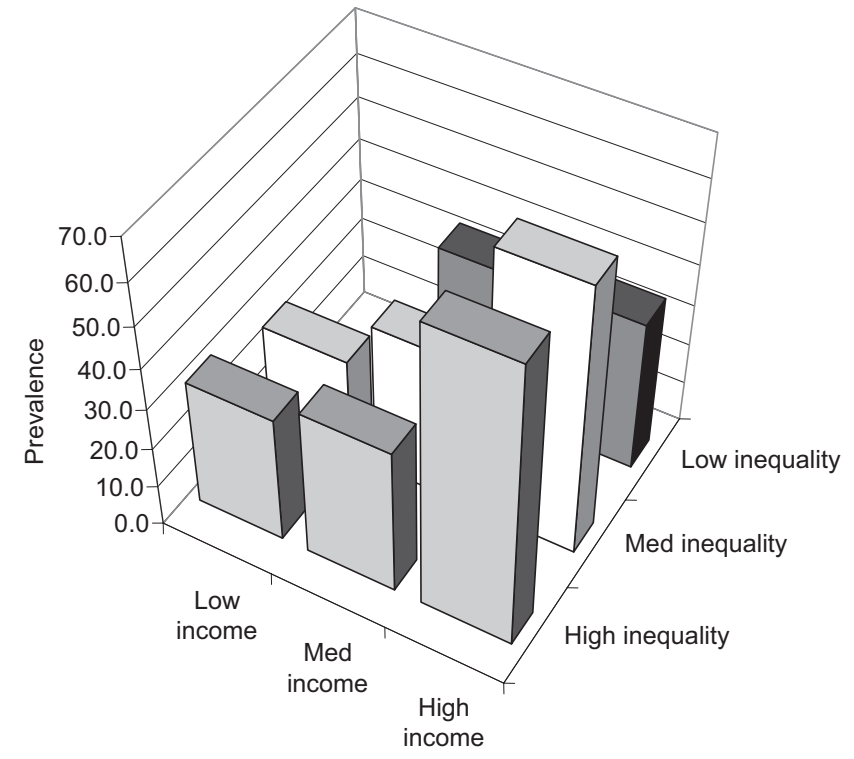

Figure 2. Gini coefficient (inequality), median income, and prevalence of alcohol drinking in New York City.

Table 2 shows three multilevel logistic regression models assessing the relationships between neighborhood median income and Gini coefficient with the individual likelihood of cigarette, alcohol, and marijuana use adjusting for individual-level variables. Neither neighborhood median income $(\beta=0.15, p=0.13)$ nor neighborhood Gini $(\beta=0.04, p=0.42)$ were associated with likelihood of cigarette use, the relationship between individual income and likelihood of cigarette use approached statistical significance $(\beta=-0.07$, $p=0.06)$. Higher neighborhood median income $(\beta=0.25, p<0.001)$, higher Gini $(\beta=0.07, p=0.02)$, and higher individual income $(\beta=0.06, p=0.02)$ all were significantly associated with greater likelihood of alcohol use. Higher neighborhood median income $(\beta=0.30, p=0.03)$ and higher Gini $(\beta=0.13, p=0.02)$ were significant predictors of greater likelihood of marijuana use, while individual income $(\beta=0.01$, $p=0.92)$ was not.

In multilevel multivariable linear models predicting frequency of cigarette use, neighborhood characteristics were not associated with frequency of cigarette use, while individual income, modeled quadratically ( $p=0.02$ and $p=0.008$ ), was significantly associated with cigarette use (Table 3 ). Neighborhood median income $(p=0.01)$, Gini coefficient $(p=0.005)$, and individual income $(p=0.005)$ all were associated with frequency of alcohol use.

\section{Discussion}

Using data from a RDD telephone survey linked to NYC neighborhoods, higher neighborhood median income and income maldistribution were found to be associated with a greater likelihood of current individual alcohol use and marijuana use, but not with cigarette use, in multilevel models adjusting for individual income and other covariates. Neighborhood median income and income distribution were also associated with greater frequency of alcohol drinking among current alcohol drinkers.

There are several reasons why contextual variables in general, and neighborhood income and income distribution in particular, may be important determinants of substance use. First, neighborhood characteristics may increase levels of psychological distress, ${ }^{39}$ and drug use may occur for relieving states of stress. ${ }^{40,41}$ There is ample research demonstrating that stressful life events occur with greater frequency in low-income neighborhoods, ${ }^{42}$ and that substance use may be a way to cope with these events. ${ }^{43}$ Second, adverse neighborhood conditions (e.g., low income, greater income maldistribution) may undermine individuals' psychological coping resources and make use of substances more likely. ${ }^{44}$ Third, it is possible that neighborhood disadvantage decreases social resources available to individuals, resulting in more limited assistance in coping with daily stresses, and fewer resources to overcome substance use once initiated. Fourth, drug-related behaviors may be related to neighborhood social norms through mechanisms unique to different neighborhoods and population groups. ${ }^{45,46}$ Fifth, differential neighborhood availability of substances may be directly associated with different levels of drug use independent of individuallevel factors. For example, it has been shown that alcohol outlet density is related to higher levels of alcohol consumption. ${ }^{47}$ Targeted advertising in particular neighborhoods may increase awareness and desirability of substances. ${ }^{48}$

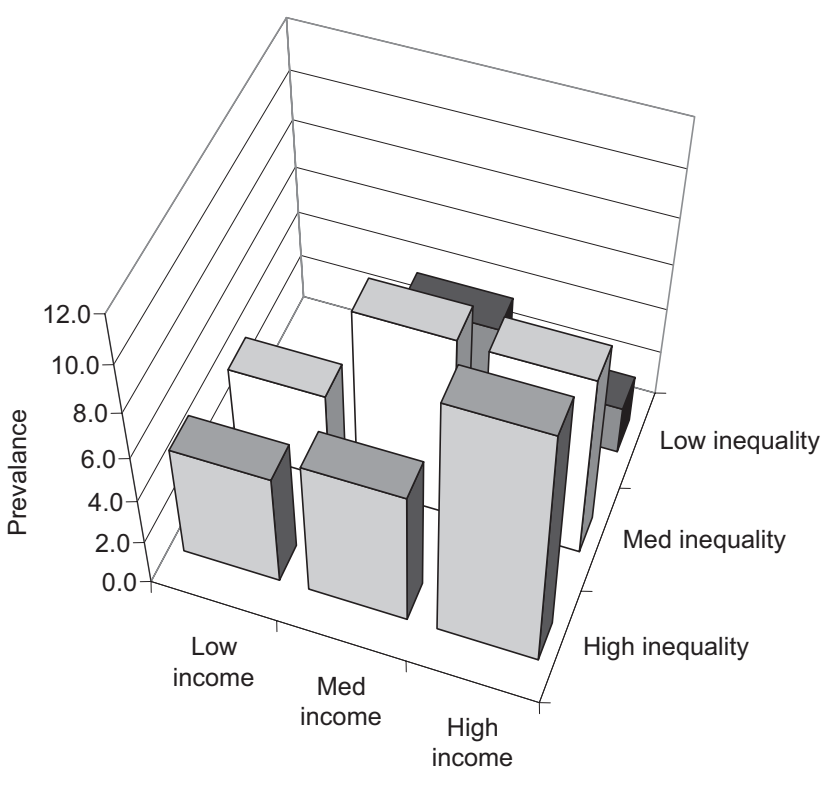

Figure 3. Gini coefficient (inequality), median income, and prevalence of marijuana smoking in New York City neighborhoods. 


\begin{tabular}{|c|c|c|c|c|c|c|c|c|c|c|c|c|}
\hline & \multicolumn{4}{|c|}{$\begin{array}{l}\text { Any cigarettes in last } 30 \text { days } \\
\qquad n=1115\end{array}$} & \multicolumn{4}{|c|}{$\begin{array}{l}\text { Any alcoholic drink in last } 30 \text { days } \\
\qquad n=1107\end{array}$} & \multicolumn{4}{|c|}{$\begin{array}{l}\text { Any marijuana in last } 30 \text { days } \\
\qquad n=1110\end{array}$} \\
\hline & Beta & $\begin{array}{l}\text { Low } \\
\text { CI }\end{array}$ & $\begin{array}{l}\text { High } \\
\text { CI }\end{array}$ & $\begin{array}{l}p \\
\text { value }\end{array}$ & Beta & $\begin{array}{l}\text { Low } \\
\text { CI }\end{array}$ & $\begin{array}{l}\text { High } \\
\text { CI }\end{array}$ & $\begin{array}{l}p \\
\text { value }\end{array}$ & Beta & $\begin{array}{l}\text { Low } \\
\text { CI }\end{array}$ & $\begin{array}{l}\text { High } \\
\text { CI }\end{array}$ & $\begin{array}{l}p \\
\text { value }\end{array}$ \\
\hline \multicolumn{13}{|l|}{ Neighborhood level } \\
\hline Median income & 0.15 & -0.04 & -0.35 & 0.13 & 0.25 & 0.09 & 0.40 & $<0.001 * *$ & 0.31 & 0.03 & 0.59 & $0.03 *$ \\
\hline Gini coefficient & 3.53 & -5.03 & 12.10 & 0.42 & 7.27 & 0.91 & 13.64 & $\mathbf{0 . 0 3}^{*}$ & 12.81 & 1.49 & 24.12 & $0.03 *$ \\
\hline \multicolumn{13}{|l|}{ Individual level } \\
\hline Income & -0.07 & -0.14 & $<0.001$ & 0.06 & 0.06 & 0.01 & 0.10 & $0.02 *$ & 0.01 & -0.13 & 0.15 & 0.92 \\
\hline Age & -0.02 & -0.03 & $<0.001$ & $0.03 *$ & -0.03 & -0.04 & -0.01 & $<0.0001 * *$ & -0.09 & -0.14 & -0.05 & $<0.001 * *$ \\
\hline Male & 0.66 & 0.11 & 1.21 & $0.02 *$ & 0.67 & 0.33 & 1.01 & $<0.001 * *$ & 0.75 & -0.09 & 1.58 & 0.08 \\
\hline Asian & -0.55 & -1.70 & 0.61 & 0.35 & -1.63 & -2.66 & -0.61 & $<0.001 * *$ & -5.56 & -7.78 & -3.35 & $<0.0001 * *$ \\
\hline African American & -0.05 & -0.64 & 0.53 & 0.86 & -0.75 & -1.29 & -0.21 & $0.01 *$ & -0.41 & -1.30 & 0.48 & 0.37 \\
\hline Hispanic & -0.18 & -1.01 & 0.64 & 0.66 & -0.85 & -1.45 & -0.24 & $0.01 *$ & -1.86 & -3.25 & -0.48 & $0.01 *$ \\
\hline Other & -0.78 & -2.29 & 0.73 & 0.31 & -0.44 & -1.65 & 0.77 & 0.48 & -0.05 & -2.41 & 2.31 & 0.97 \\
\hline High school/GED & 0.46 & -0.26 & 1.18 & 0.21 & 0.03 & -0.97 & 1.02 & 0.96 & -0.99 & -2.56 & 0.58 & 0.22 \\
\hline Some college & 0.54 & -0.25 & 1.34 & 0.18 & 0.39 & -0.58 & 1.35 & 0.44 & -0.34 & -1.81 & 1.12 & 0.65 \\
\hline College graduate & -0.21 & -1.03 & 0.61 & 0.61 & 0.72 & -0.41 & 1.84 & 0.21 & -1.59 & -3.31 & 0.14 & 0.07 \\
\hline Graduate work & -1.08 & -2.09 & -0.07 & $0.04 *$ & 0.78 & -0.26 & 18.1 & 0.14 & -1.58 & -3.60 & 0.43 & 0.12 \\
\hline
\end{tabular}

$* p=<0.05$

$* * p=<0.001$ (all bolded).

CI, confidence interval.

These postulated mechanisms to explain potential relationships between neighborhood context and substance use suggest that more disadvantaged neighborhoods (characterized by lower income or by greater income maldistribution) would be expected to have higher prevalence and frequency of substance use. This study's observations, taken in concert with other related work, suggest that the relationship between neighborhood context and substance use is far more nuanced. Income and income distribution were both determi- nants of alcohol use in multilevel models. However, neighborhoods with higher median income had a greater likelihood of alcohol use. This finding is similar to work by Pollack et al. ${ }^{24}$ indicating higher odds of heavy alcohol consumption among residents in the least-deprived neighborhoods in California, but stands in contrast to other work suggesting that poorer neighborhood conditions are associated with greater alcohol use. ${ }^{23}$ This suggests that stress hypotheses (which may explain a relationship between lower income or greater

\begin{tabular}{|c|c|c|c|c|c|c|c|c|}
\hline & \multicolumn{3}{|c|}{$\begin{array}{c}\text { Number of cigarettes in last } 30 \\
\text { days, among smokers } \\
n=258\end{array}$} & \multicolumn{3}{|c|}{$\begin{array}{c}\text { Number of alcoholic drinks in } \\
\text { last } 30 \text { days, among drinkers } \\
n=562\end{array}$} & \multirow[b]{2}{*}{$\begin{array}{l}\text { High } \\
\text { CI }\end{array}$} & \multirow[b]{2}{*}{$p$ value } \\
\hline & Beta & $\begin{array}{l}\text { Low } \\
\text { CI }\end{array}$ & $\begin{array}{l}\text { High } \\
\text { CI }\end{array}$ & $p$ value & Beta & $\begin{array}{l}\text { Low } \\
\text { CI }\end{array}$ & & \\
\hline \multicolumn{9}{|l|}{ Neighborhood level } \\
\hline Median income & -24.95 & -63.05 & 13.16 & 0.20 & 3.01 & 0.64 & 5.39 & $0.01 *$ \\
\hline Gini coefficient & -872.50 & -2628.64 & 883.64 & 0.33 & 159.46 & 47.08 & 271.85 & $0.01 *$ \\
\hline \multicolumn{9}{|l|}{ Individual level } \\
\hline Household income & 69.61 & 14.02 & 125.20 & $0.01 *$ & -0.90 & -1.53 & -0.28 & $<0.001 *$ \\
\hline Household income & -4.63 & -7.97 & -1.29 & $0.01 *$ & - & - & - & - \\
\hline Age & 4.01 & 0.68 & 7.35 & $0.02 *$ & 0.01 & -0.26 & 0.29 & 0.92 \\
\hline Male & 102.30 & 20.08 & 184.52 & $0.01 *$ & 6.84 & 0.44 & 13.24 & $0.04^{*}$ \\
\hline Asian & -98.50 & -248.68 & 51.67 & 0.20 & -1.06 & -15.40 & 13.28 & 0.88 \\
\hline African American & -169.06 & -278.37 & -59.74 & $<0.001 *$ & -3.18 & -15.40 & 9.04 & 0.61 \\
\hline Hispanic & -122.30 & -261.38 & 16.79 & 0.08 & -3.63 & -14.19 & 6.94 & 0.50 \\
\hline Other & -287.09 & -473.08 & -101.10 & $<0.001 * *$ & -13.95 & -26.78 & -1.11 & $0.03 *$ \\
\hline High school/GED & 40.01 & -100.73 & 180.75 & 0.58 & 7.43 & -7.45 & 22.30 & 0.33 \\
\hline Some college & -8.27 & -168.84 & 152.30 & 0.92 & 5.47 & -4.37 & 15.31 & 0.28 \\
\hline College graduate & 96.10 & -153.65 & 345.84 & 0.45 & 6.62 & -4.95 & 18.18 & 0.26 \\
\hline Graduate work & 6.88 & -319.91 & 333.68 & 0.97 & -0.96 & -11.39 & 9.47 & 0.86 \\
\hline
\end{tabular}


income maldistribution and alcohol use) are not a sufficient explanation for the role of neighborhood context in shaping alcohol use. In the case of alcohol use, it is likely that social norms play a role in determining its use that is at least comparable to the role played by contextual stress. This study did not find any associations between either individual- or neighborhood-level income and smoking. This adds to the discrepancy in the literature between work that has shown that contextual factors were associated with cigarette use $\mathrm{e}^{9,18-21}$ and work that has not. ${ }^{49}$ These discrepancies may be explained both by the methodologic differences (including contextual unit of analysis) and by the potential presence of multiple mechanisms, each relevant in different contexts, that determine substance use.

The literature about contextual determinants of illicit drug use is sparse ${ }^{50}$ Furthermore, empiric studies that have assessed contextual determinants of alcohol, cigarette, and marijuana use in the same population sample could not be found. This study suggests similarities between the determinants of alcohol and marijuana use in contrast to cigarette use. It is plausible that because cigarettes have a greater potential for dependence than either alcohol or marijuana, ${ }^{51}$ current cigarette use is determined by earlier characteristics of the life course, while contemporaneous contextual variables may have an effect on alcohol and marijuana use. This observation, if replicated, has substantial implications for prevention efforts and merits further research.

The observations made in this study must be interpreted with caution. Data from a study of residents of NYC in the aftermath of the September 11 attacks were used. It is possible that the relationships observed here are particular to a period of heightened concern due to a national disaster and are not generalizable to other contexts. However, these data were collected more than 6 months after the attacks, and there is no evidence that the increase in substances used in NYC after this disaster was differential across geographic areas, suggesting that this concern is unlikely to affect the observations documented here. Also, the survey data used here were collected through telephone interviews, raising the possibility of under-reporting of substances used. This is again unlikely given the comparability of substance use documented here to national estimates and the growing evidence to suggest that estimates obtained through telephone assessments can validly replicate those from in-person assessments. ${ }^{52,53}$ Although available relevant individual and neighborhood-level variables were controlled for, it is possible that residual cross-level confounding or confounding by covariates not considered here could explain some of the observed relationships among neighborhood characteristics and substance use measures.

Consistent with previous research, ${ }^{30}$ community districts were used as proxies for neighborhoods in NYC.
Defining relevant neighborhood units is challenging, and these units, while large, are probably more meaningful analytic units than census tracts or ZIP codes, the most commonly used units of analysis in the study of neighborhood-level effects. ${ }^{4,29}$ Census data from 2000 were also used, and it is difficult to know how well this information represents conditions of neighborhoods in NYC in 2002, and if any changes may account for some of the observed associations. Also, inferences about the patterns of marijuana use prevalence are limited by the relatively low prevalence of marijuana use. Finally, the data pertain strictly to substance use, and inferences should not be extended from these observations to either substance abuse or dependence.

Notwithstanding these limitations, these data suggest that neighborhood income and income distribution are associated with use of alcohol and marijuana, but not cigarettes. Further research should investigate specific pathways that explain the relationship between neighborhood characteristics and use of different substances, as the elucidation of these pathways may be useful when developing interventions to reduce use of these substances.

The authors would like to thank Emily Gibble for assistance with manuscript preparation. Funded in part by the National Institutes of Health (grant DA 017642 to SG).

No financial conflict of interest was reported by the authors of this paper.

\section{References}

1. Wright T. State estimates of substance use from the 2000 National Household Survey on Drug Abuse: findings. Rockville MD: Substance and Mental Health Services Administration, Office of Applied Studies, 2000.

2. Galea S, Nandi A, Vlahov D. The social epidemiology of substance use. Epidemiol Rev 2004;26:36-52.

3. Galea S, Rudenstine S, Vlahov D. Drug use, misuse, and the urban environment. Drug Alcohol Rev 2005;24:127-36.

4. Diez-Roux AV. Investigating neighborhood and area effects on health. Am J Public Health 2001;91:1783-9.

5. Pickett KE, Pearl K. Multilevel analyses of neighborhood socioeconomic context and health outcomes: a critical review. J Epidemiol Comm Health 2001;55:111-22.

6. Winkelstein W. Epidemiological considerations underlying the allocation of health and disease resources. Int J Epidemiol 1972;1:69-74.

7. Yen IH, Kaplan GA. Neighborhood social environment and risk of death: multilevel evidence from the Alameda County Study. Am J Epidemiol 1999;149:898-907.

8. Finkelstein MM, Jerrett M, DeLuca P, et al. Relation between income, air pollution and mortality: a cohort study. CMAJ 2003;169:397-402.

9. Diez-Roux AV, Nieto F, Muntaner C, et al. Neighborhood environments and coronary heart disease: a multilevel analysis. Am J Epidemiol 1997;146:48-63.

10. Kozyrskyj AL, Hildes-Ripstein GE. Assessing health status in Manitoba children: acute and chronic conditions. Can J Public Health 2002;93(suppl 2):S44-9.

11. Rodgers GB. Income and inequality as determinants of mortality: an international cross section analysis. Pop Stud 1979;31:182-91.

12. Lynch J, Smith GD, Hillemeier M, Shaw M, Raghunathan T, Kaplan G. Income inequality, the psychosocial environment and health: Comparisons of wealthy nations. Lancet 2001;358:1285-7.

13. Ross NA, Wolfson MC, Dunn JR, Berthelot J-M, Kaplan GA, Lynch JW. Relation between income inequality and mortality in Canada and in the 
United States: cross-sectional assessment using census data and vital statistics. BMJ 2000;320:898-902.

14. Mellor JM, Milyo J. Is exposure to income inequality a public health concern? Lagged effects of income inequality on individual and population health. Health Serv Res 2003;38:137-51.

15. Kawachi I, Kennedy BP, Lochner K, Prothrow-Stith D. Social capital, income inequality and mortality. Am J Public Health 1997;87:1491-8.

16. Lynch JW, Kaplan GA. Understanding how inequality in the distribution of income affects health. J Health Psychol 1997;2:297-314.

17. Curry SJ, Wagner EH, Cheadle A, et al. Assessment of community-level influences on individuals' attitudes about cigarette smoking, alcohol use, and consumption of dietary fat. Am J Prev Med 1993;9:78-84.

18. Kleinschmidt I, Hills M, Elliott P. Smoking behavior can be predicted by neighborhood deprivation measures. J Epidemiol Community Health 1995;49(suppl 2):S72-7.

19. Jones K, Duncan C. Individuals and their ecologies: analyzing the geography of chronic illness within a multilevel modeling framework. Health and Place 1995;1:27-40.

20. Reijneveld SA. The impact of individual and area characteristics on urban socioeconomic differences in health and smoking. Int J Epidemiol 1998;27:33-40.

21. Ecob R, MacIntyre S. Small area variations in health related behaviors; do these depend on the behavior itself, its measurement, or on personal characteristics? Health and Place 2000;6:261-74.

22. Duncan C, Jones K, Moon G. Health-related behaviour in context: a multilevel modeling approach. Soc Sci Med 1996;42:817-30.

23. Hill TD, Angel RJ. Neighborhood disorder, psychological distress, and heavy drinking. Soc Sci Med 2005;61:965-75.

24. Pollack CE, Cubbin C, Ahn D, Winkleby M. Neighbourhood deprivation and alcohol consumption: does the availability of alcohol play a role? Int J Epidemiol 2005;34:772-80.

25. Steptoe A, Feldman PJ. Neighborhood problems as sources of chronic stress: Development of a measure of neighborhood problems, and associations with socioeconomic status and health. Ann Behav Med 2001;23:177-85.

26. Galea S, Ahern J, Vlahov D, et al. Income distribution and risk of fatal drug overdose in New York City neighborhoods. Drug Alcohol Depend 2003;70:139-48

27. Galea S, Vlahov D, Resnick H, et al. Trends in probable posttraumatic stress disorder in New York City after the September 11 terrorist attacks. Am J Epidemiol 2003;158:514-24.

28. Vlahov D, Galea S, Ahern J, Resnick H, Kilpatrick D. Sustained increased consumption of cigarettes, alcohol and marijuana among Manhattan residents after September 11, 2001. Am J Pub Health 2004;94:253-4.

29. Messner SF, Tardiff K. Economic inequality and levels of homicide: an analysis of urban neighborhoods. Criminology 1986;24:297-317.

30. Marzuk PK, Tardiff K, Leon AC, et al. Poverty and fatal accidental drug overdoses of cocaine and opiates in New York City: an ecological study. Am J Drug Alcohol Abuse 1997;23:221-8.

31. Suecoff SA, Avner JR, Chou KJ, Crain EF. A comparison of New York City playground hazards in high- and low-income areas. Arch Pediatr Adolesc Med 1999;153:363-6.

32. U.S. Census Bureau. Census 2000 summary tape, file 3A (STF 3A). Washington DC: U.S. Dept of Commerce, 2002. Available at: www.census. gov/ftp/pub/populatin/www/estimates/co_crh.html.
33. Blakely TA, Lochner K, Kawachi I. Metropolitan area income inequality and self-rated health-a multi-level study. Soc Sci Med 2002;54:65-77.

34. Judge K, Paterson I. Poverty, income inequality, and health. Treasury Working Papers 01-29. Wellington, New Zealand, 2001. Available at: www.treasury.govt.nz/workingpapers/2001/01-29.asp.

35. Deaton A. Health, inequality, and economic development. J Econ Lit 2003;41:113-58.

36. Zeger SL, Liang K-Y. Longitudinal data analysis for discrete and continuous outcomes. Biometrics 1986;42:121-30.

37. Merlo J. Multilevel analytical approaches in social epidemiology: measures of health variation compared with traditional measures of association. J Epidemiol Community Health 2003;57:550-2.

38. Substance Abuse and Mental Health Services Administration. Overview of findings from the 2002 Survey on Drug Use and Health. Rockville MD: Office of Applied Studies, 2003. NHSDA series H-21. Available at: www.oas. samhsa.gov/NHSDA/2k2NSDUH/Overview/2k2Overview.htm.

39. Aneshensel CS, Sucoff CA. The neighborhood context of adolescent mental health. J Health Soc Behav 1996;37:293-310.

40. Rhodes JE, Jason LA. A social stress model of substance abuse. J Consult Clin Psychol 1990;58:395-401.

41. Lindenberg CS, Reiskin HK, Gendrop SC. The social stress model of substance abuse among childbearing-age women: a review of the literature. J Drug Educ 1994;24:253-68.

42. Fang J, Madhavan S, Bosworth W, Alderman MH. Residential segregation and mortality in New York City. Soc Sci Med 1998;47:469-76.

43. Boardman JD, Finch BK, Ellison CG, Williams DR, Jackson JS. Neighborhood disadvantage, stress, and drug use among adults. J Health Soc Behav 2001;42:151-65.

44. Wilson JQ. Foreword. In: Kelling GL, Coles CM, eds. Fixing broken windows: restoring order and reducing crime in our communities. New York: Simon and Schuster, 1996:pp. 1-14.

45. Linsky AS, Colby JP Jr, Straus MA. Drinking norms and alcohol-related problems in the United States. J Stud Alcohol 1986;47:384-93.

46. Kaplan CP, Napoles-Springer A, Stewart SL, Perez-Stable EJ. Smoking acquisition among adolescents and young Latinas: the role of socioenvironmental and personal factors. Addict Behav 2001;26:531.

47. Scribner RA, Cohen DA, Fisher W. Evidence of a structural effect for alcohol outlet density: a multi-level analysis. Alcohol Clin Exp Res 2000;24:188-95.

48. Donovan RJ, Jancey J, Jones S. Tobacco point of sale advertising increases positive brand user imagery. Tob Control 2002;11:191-4.

49. Tseng M, Yeatts K, Millikan R, Newman B. Area-level characteristics and smoking in women. Am J Public Health 2001;91:1847-50.

50. Galea S, Ahern J, Vlahov D. Contextual determinants of drug use risk behavior: A theoretic framework. J Urban Health 2003;80(suppl 3):i50-8.

51. Kandel D, Chen K, Warner LA, Kessler RC, Grant B. Prevalence and demographic correlates of symptoms of last year dependence on alcohol, nicotine, marijuana and cocaine in the U.S. population. Drug Alcohol Depend 1997;10:44:11-29.

52. Midanik LT, Greenfield TK. Telephone versus in-person interviews for alcohol use: Results of the 2000 National Alcohol Survey. Drug Alcohol Depend 2003;72:209-14

53. Nelson DE, Powell-Griner E, Town M, Kovar MG. A comparison of national estimates from the National Health Interview Survey and the Behavioral Risk Factor Surveillance System. Am J Public Health 2003;93:1335-41. 